\title{
Niveles de desarrollo $y$ efectos sobre el medio ambiente
}

\author{
Fondo de PoBlación \\ DE LAS NaCIONES UNIDAS
}

\section{Determinación de los efectos DE LA ACTIVIDAD HUMANA}

Actualmente, hay más personas que utilizan más recursos y con mayor intensidad que en ningún otro momento de la historia humana. Los sistemas de agua dulce, las tierras de cultivo, los bosques, las pesquerías y la diversidad biológica muestran signos de alteración a escala local, regional y mundial. La creciente presión sobre el medio ambiente es consecuencia, por una parte, del aumento de la riqueza - es decir, más consumo, más contaminación y más desechos- y por la otra, de la persistente pobreza, esto es, falta de recursos y de tecnología para usarlos y falta de poder para cambiar esas circunstancias. La creciente cantidad de seres humanos desempeña un papel en ambos casos. En los últimos 50 años, por ejemplo, se ha duplicado en todo el mundo
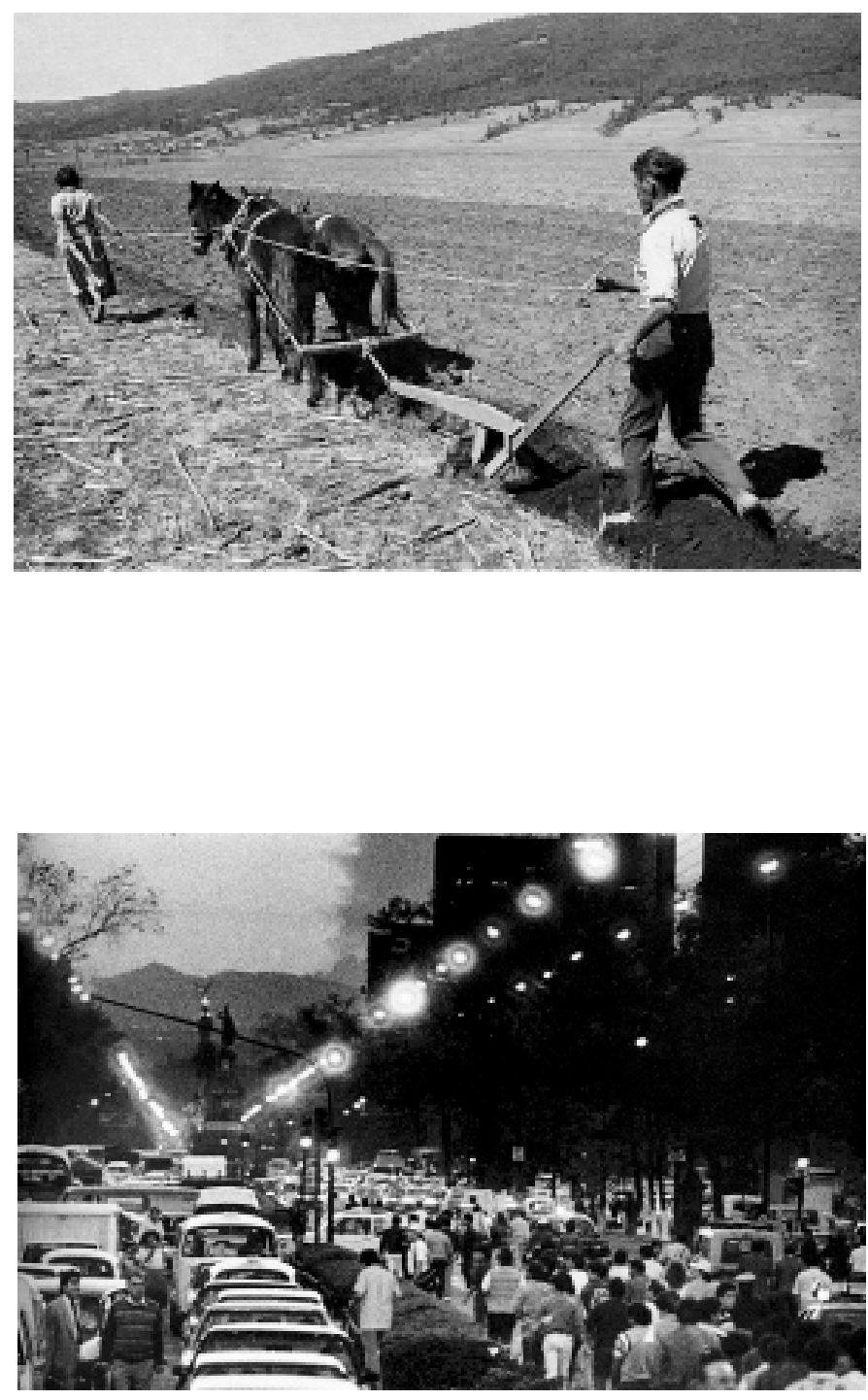
el uso de la leña; el World-

watch Institute atribuye este aumento en gran medida al crecimiento de la población. Pero la sextuplicación en el uso del papel ocurrida después de 1950 se atribuye principalmente al aumento de la riqueza y a los múltiples usos de productos de papel en un ámbito cada vez más urbano.

El tamaño, el crecimiento, la distribución y los desplazamientos de la población contribuyen a determinar las relaciones entre las personas y el medio ambiente. Cantidades similares de personas

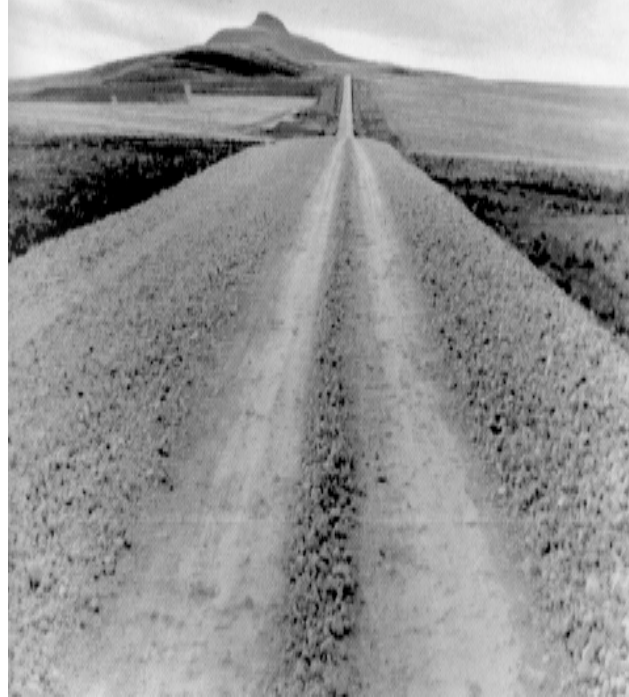

este enfoque ha sido útil para demostrar que la dinámica de la población es un factor fundamental en el cambio del medio ambiente.

Por ejemplo, a partir de 1970, las emisiones de anhídrido carbónico per cápita han permanecido relativamente invariables a escala mundial, mientras que el PIB per cápita ha aumentado en todas las regiones, tanto en las más como menos desarrolladas. ${ }^{5}$ Esto significa que los adelantos tecnológicos han compensado los efectos del mayor consumo. ${ }^{6}$ Que pueden tener efectos muy diferentes sobre el ambiente, en función, por ejemplo, de las instituciones sociales, los medios de producción, las normas de propiedad y las modalidades de gobernabilidad. ${ }^{1}$ El acceso a la educación, a los servicios de salud y a las oportunidades económicas, los niveles de consumo y los diferenciales de género (la calidad del capital humano) son todos factores que tienen influencia.

El factor determinante de los efectos es la escala. Hace treinta años, Paul Ehrlich y J. Holdren describieron esta relación en una ecuación que hoy es famosa: ${ }^{2}$ I = PAT, es decir, los efectos de las personas sobre su medio ambiente (I) son producto del tamaño de la población ( $P$ ), de la riqueza (A, que representa el producto per cápita o el nivel de consumo) y de la tecnología ( $T$, que representa el producto unitario o la eficiencia en la producción).

Esta ecuación se ha utilizado con frecuencia ${ }^{3}$ pero también se le ha criticado o modificado con regularidad. ${ }^{4}$ Su principal defecto es que los factores de la relación no son independientes, sino que están vinculados entre sí de maneras complejas. No obstante, las emisiones de anhídrido carbónico sigan aumentando al mismo ritmo que el tamaño de la población dependerá de las tendencias económicas y sociales, de la respuesta institucional a los problemas del medio ambiente y del ritmo del cambio tecnológico.

\section{LA POBREZA Y EL MEDIO AMBIENTE}

Pese a que la riqueza mundial ha aumentado pronunciadamente y se estima ahora en 24 billones de dólares anuales, hay en todo el mundo unos 1,200 millones de personas que viven con menos de un dólar diario, situación clasificada como de extrema pobreza y caracterizada por el hambre, el analfabetismo, la vulnerabilidad, la enfermedad y la muerte prematura. La mitad de los habitantes del mundo viven con dos dólares diarios o menos. ${ }^{7}$

Hay más de diez millones de personas que no pueden satisfacer sus necesidades básicas de alimento, agua, saneamiento, atención de la salud, vivienda y educación. De los 4,400 millones de personas que viven en países en desarrollo, casi un $60 \%$ carecen 
de saneamiento básico, casi un tercio de esas personas no tienen acceso al abastecimiento de agua no contaminada, una cuarta parte carece de vivienda adecuada, un $20 \%$ no tiene acceso a servicios modernos de salud y un $20 \%$ de los niños no asisten a la escuela. En todo el mundo, 1,100 millones de personas están desnutridas y no pueden satisfacer las normas mínimas de consumo energético y proteínico en sus dietas, y las deficiencias de micronutrientes están generalizadas. ${ }^{8}$ Hay en los países en desarrollo casi 2,000 millones de personas anémicas. ${ }^{9}$

La eliminación de la pobreza ha sido un objetivo internacional a partir de 1960. Después de los notables adelantos logrados entre 1970 y 1990, en el decenio de 1990 el ritmo de reducción de la pobreza disminuyó hasta sólo un tercio del necesario para satisfacer los compromisos de las Naciones Unidas de bajar a la mitad los niveles de pobreza hacia el año 2015.

Si bien debido a las riquezas se consume energía y se producen residuos a ritmos muy superiores, los efectos de la pobreza destruyen también el medio ambiente. En consecuencia, la atención mundial se ha centrado en la compleja relación entre degradación del ambiente, pobreza y sustentabilidad. Comprender esa relación puede ser la clave para eliminar la pobreza y salvar las desiguladades entre los más ricos y los menos ricos, así como para alcanzar el objetivo del desarrollo sostenible.

\section{UNA INTERACCIÓN COMPLEJA}

Las presiones demográficas van en aumento en muchas zonas pobres y ecológicamente frágiles, tanto urbanas como rurales. En muchas de esas zonas donde ya hay altas tasas de fecundidad, muchas más personas acuden impulsadas por la falta de tierras para los cultivos de subsistencia, por las políticas económicas que alientan los grandes terratenientes, por la agricultura intensiva y de cultivos comerciales, así como por la pobreza y las altas densidades de población en otras zonas.

Por ejemplo, en la Península de Yucatán (México), en la Reserva de la Biosfera de Calakmul y en torno suyo se está intensificando la aplicación de técnicas de roza, tumba y quema para la agricultura y la explotación maderera a causa de la rápida inmigración y las altas tasas de fecundidad. Debido a las incesantes presiones demográficas, los agricultores de subsistencia han talado los bosques de la sierra de Garo, en la zona nororiental de la India. La creciente pobreza en comunidades costeras y el rápido crecimiento de la población en las grandes ciudades de la costa del África occidental también están impulsando la destrucción de los pantanos de manglares para obtener leña y explotar los recursos pesqueros utilizando dinamita en las aguas donde se crían peces.

En esos ejemplos y en muchos otros, los pobres son los agentes más visibles de la destrucción de ambientes degradados. Los pobres dependen en gran medida de los recursos naturales para obtener ingresos directos y su pobreza les ofrece pocas opciones. En el caso de Garo, no se disponía de tierras alternativas y en la costa del África occidental, la demanda urbana de pescado y leña ofreció una fuente inmediata de ingresos. En estos casos y en otros, los pobres están en el extremo de una larga cadena de causas y efectos. Son los mensajeros de la falta de sustentabilidad, y no sus agentes.

Un desglose de las pautas de consumo indica que la huella ecológica (véase pp. 22ss) de los más ricos es mucho más profunda que la de los pobres y, en muchos casos, excede la capacidad de regeneración de la Tierra.

En la mayoría de los casos, son los agricultores más ricos quienes emprenden talas en gran escala, quienes utilizan desmedidamente los productos químicos agrícolas, quienes explotan excesivamente los recursos de aguas subterráneas con destino al riego, quienes utilizan excesivamente las tierras de pastoreo y 
quienes explotan desmesuradamente los suelos con cultivos para la exportación. Las estructuras distorsionadas de precios perpetúan el derroche en el uso de Ios insumos. En Gujarat (India), los agricultores tribales pobres deben pagar el costo total del agua de riego extraída con bombas que fueron proporcionadas por conducto de una organización no gubernamental, mientras que los agricultores más pudientes reciben agua subsidiada en virtud de planes estatales.

Los grupos de más altos ingresos consumen más energía y producen más desechos que los pobres, ya que estos últimos deben aprovechar hasta el último mendrugo. En Pakistán, los hogares de muy bajos ingresos gastan 1/ 30 del combustible que consumen los hogares ricos, aun cuando dedican mucho más tiempo y energía a recoger ese combustible. Las comunidades rurales seguirán dependiendo en gran medida de la agricultura y los recursos naturales para sus medios de vida. La degradación del medio ambiente sólo profundizará su pobreza, de modo que la conservación del ambiente y la mitigación de la pobreza son objetivos paralelos. En la mayoría de las situaciones en que disfrutan de una tenencia segura, los pobres efectuarán inversiones para proteger sus tierras y su medio ambiente.

El control local puede ser importante: los estudios indican que ha mejorado el estado de los bosques de Nepal a partir del momento en que se descentralizó el ordenamiento de los recursos forestales hacia las comunidades. El Programa conjunto de ordenamiento forestal de la India, que también delega en los pobladores locales el ordenamiento de los recursos, ha tenido beneficios similares sobre el ambiente, en zonas como la región sudoccidental de Bengala. El control local puede ser más eficaz que las acciones gubernamentales para limitar las actividades ilegales de tala, pesca, uso del agua y robo, pero la participación gubernamental puede contribuir a compensar el alto costo y el aplazamiento de los beneficios de las inversiones en conservación.
A lo largo de las generaciones, los agricultores pobres han acumulado grandes cantidades de conocimientos acerca de las prácticas de sostenibilidad del medio ambiente. Algunas prácticas, entre ellas la rotación de los cultivos, han sostenido a los pobres durante siglos, hasta que las poblaciones aumentaron demasiado o intervinieron otros factores. Las prácticas tradicionales pueden incorporar la comprensión de las condiciones locales, que no son inmediatamente evidentes para observadores externos, por alto que sea su nivel de conocimientos. En las zonas montañosas de Sumatra, los agricultores utilizan simples embalses de piedra para crear sistemas de riego a lo largo de pequeños cursos de agua. Si bien al parecer esas estructuras dan lugar a filtraciones y son ineficientes, las filtraciones aseguran una distribución equitativa del agua en toda la comunidad.

Cuando los pobres se desplazan hacia nuevos ámbitos o cuando se altera el equilibrio en el ambiente que habían ocupado debido, por ejemplo, al rápido aumento de las poblaciones, puede haber un período en que es necesario un nuevo aprendizaje y durante el cual puede haber degradación hasta cierto punto. Pero imponer soluciones técnicas estandarizadas que hagan caso omiso de los conocimientos autóctonos, o los eliminen, puede tener efectos ecológicos desastrosos.

El crecimiento de la población no necesariamente menoscaba el carácter sostenible del medio ambiente, pero afecta las opciones disponibles y las perspectivas de intervención. Aun cuando la degradación ocurre invariablemente en las etapas iniciales, cuando hay aumentos en las densidades de población que eran muy bajas, las etapas siguientes dependen de la confluencia de varios factores. Si las inversiones necesarias para mejorar la tierra son demasiado grandes o si las utilidades se demoran demasiado, a medida que la población va aumentando habrá inevitablemente mayor degradación. En otros casos, cuan- 


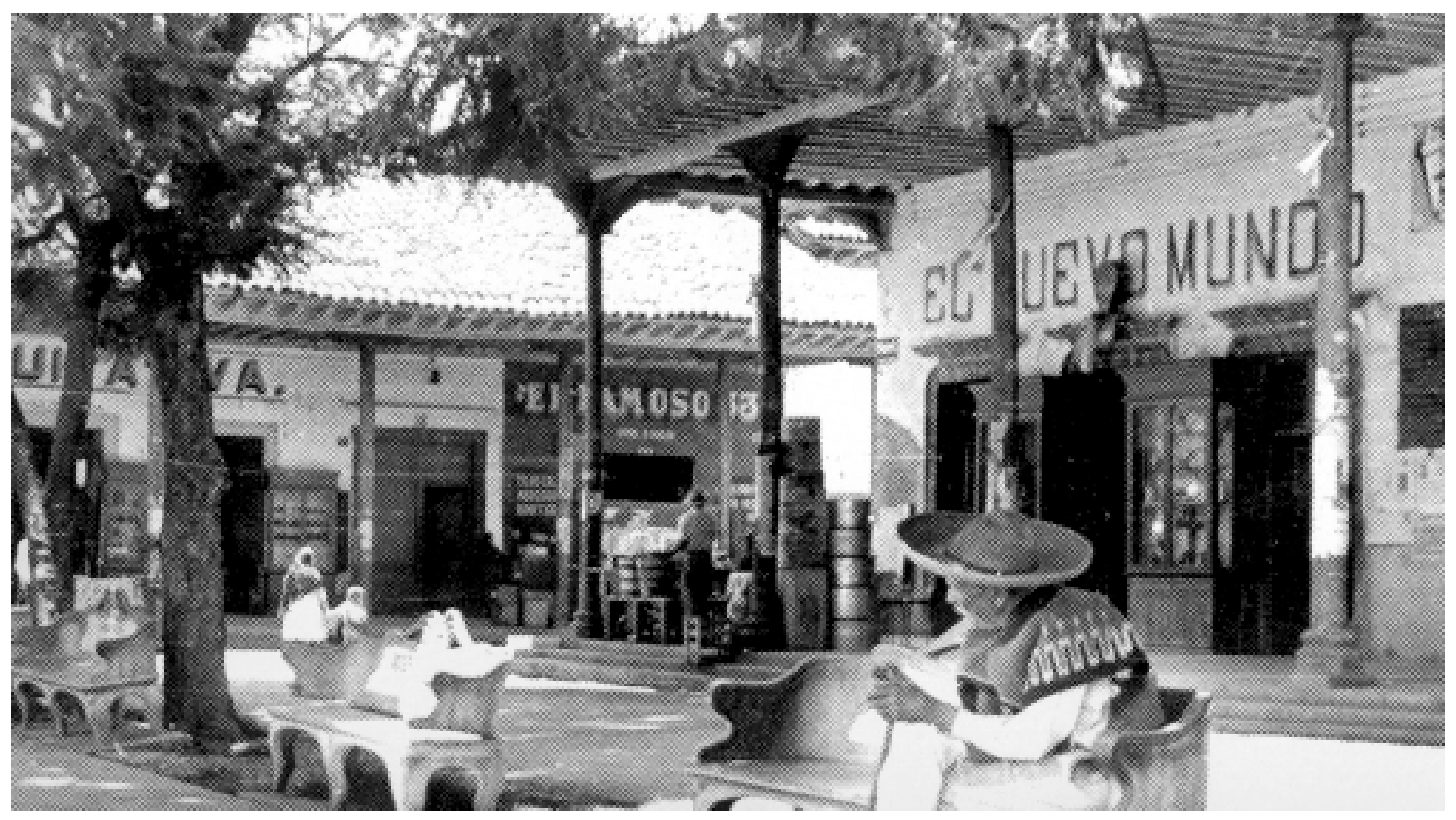

do una mayor población puede redundar en menores pagos per cápita para inversiones fijas (como en tecnología de captación de agua), en realidad es posible que mejoren la sostenibilidad y la productividad en un ámbito propicio.

Si se alentara y apoyara a los países en desarrollo cuyas poblaciones están creciendo rápidamente para que adopten tecnologías menos contaminantes, sería posible mitigar la degradación del medio ambiente. De mantenerse las actuales tasas de crecimiento, se prevé que en los próximos 20 años habrán de triplicarse las emisiones de gases de efecto invernadero en Asia. Una tecnología eficaz, si fuera costeable, podría reducir las emisiones.

LA MUNDIALIZACIÓN Y LA POBREZA

En los últimos 20 años, más de 100 países en desarrollo y en transición han comenzado a emprender medidas de reforma para mejorar la eficiencia de sus economías. Esos conjuntos de medidas de reforma suelen incluir disciplina fiscal, reducción de los déficit presupuestarios, disminución de los subsidios, restructuración impositiva, liberalización financiera, tasas de interés determinadas por el mercado, tipos de cambio competitivos y estables, liberalización del intercambio comercial, aliento a la inversión extranjera directa, privatización de las empresas estatales, desregulación de sectores industriales protegidos y mayores garantías de los derechos de propiedad.

Esas reformas han tenido el propósito de aumentar la competitividad de los países en el mercado mundial. Durante ese período, ha aumentado pronunciadamente el comercio internacional, aun cuando fuera de las economías de mercado más adelantadas, sólo unos pocos países en desarrollo han acusado aumentos. El deseo de integración en la economía mundial o de compensación de las pérdidas sufridas en las crisis financieras ha llevado a muchos países en desarrollo a intensificar la explotación de sus recursos naturales.

Es evidente que la mundialización ha fomentado la prosperidad general y estimulado el crecimien- 


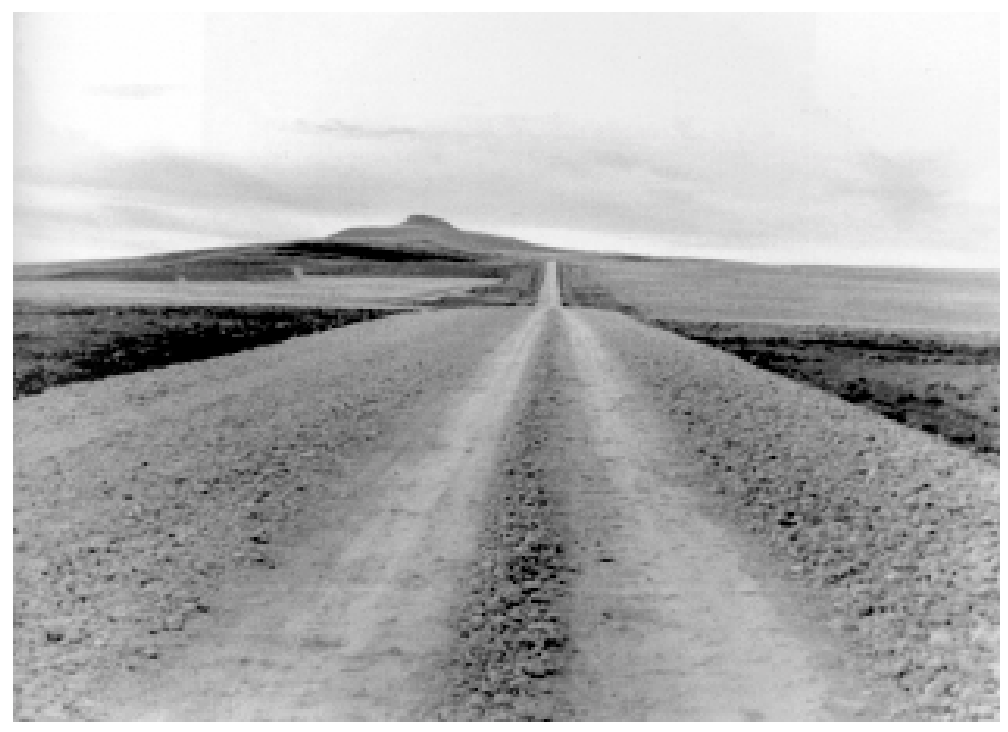

MEDICIÓN DE LAS DIMENSIONES

DE LA POBREZA

Tradicionalmente, los economistas han definido a la pobreza en función de los ingresos, utilizando una norma relativa, como la mediana de ingresos en el país, o bien una norma absoluta, como el costo de una canasta típica de bienes y servicios. Definiciones más recientes también abarcan mediciones de la salud, la educación, la seguridad, la voz en materia política y la discriminación. En el Informe sobreDesarrollo Mundial 2000-2001"1 se mide a la pobre-

to. También ha agravado la desigualdad en los ingresos y la degradación del medio ambiente. Aun cuando los porcentajes de pobreza han disminuido, el número de personas que viven en la pobreza ha aumentado sostenidamente y en muchos países en desarrollo, el promedio de ingresos ha permanecido a un nivel bajo. Al mismo tiempo, la degradación del medio ambiente es peor que en ningún otro período comparable de la historia humana. Hay un claro vínculo entre la degradación del medio ambiente y el aumento de la desigualdad que acompaña a la mundialización: debido al aumento de la pobreza, muchos pobres están aumentando la presión que ejercen sobre recursos naturales frágiles, a fin de poder sobrevivir.

Algunos $\operatorname{críticos}^{10}$ han llegado a la conclusión de que, si bien la mundialización ha conducido a introducir notables reformas económicas, muchos funcionarios encargados de formular las políticas públicas han hecho caso omiso de las reformas paralelas de orden social, medioambiental e institucional necesarias para prevenir que se sigan agravando la desigualdad, la pobreza y la degradación del entorno. za en función de tres aspectos: oportunidad, potenciación y seguridad. El Banco Mundial incluye otra dimensión: capacidades. ${ }^{12}$

Estos aspectos tienen múltiples determinantes, pero hay un factor común a todos ellos: la sostenibilidad del medio ambiente.

La oportunidad refleja el ingreso individual, el consumo y el nivel de desigualdad de una sociedad. Es posible mejorar la oportunidad mediante un ámbito económico estable, una distribución equitativa de los bienes y una fácil disponibilidad de infraestructura. Entre las acciones concretas relativas al medio ambiente que mejoran el grado de oportunidad se encuentran el aumento de la productividad de tierras y pesquerías y las estructuras de precios sensibles a las cuestiones del medio ambiente.

La potenciación refleja la participación individual en la adopción de decisiones y queda fortalecida por la descentralización, la transparencia y la obligación de rendir cuentas en todos los aspectos de la gobernabilidad, incluido el ordenamiento de los recursos naturales.

La seguridad refleja el grado de protección individual contra sacudidas económicas y violencia perso- 
nal. Entre las acciones relativas al medio ambiente cabe citar los mecanismos de pronóstico y prevención de desastres y la protección contra la explotación ilegal de recursos.

Las capacidades reflejan el nivel de alfabetización y de salud del individuo. El acceso a agua apta para el consumo y a un mejor sanea-

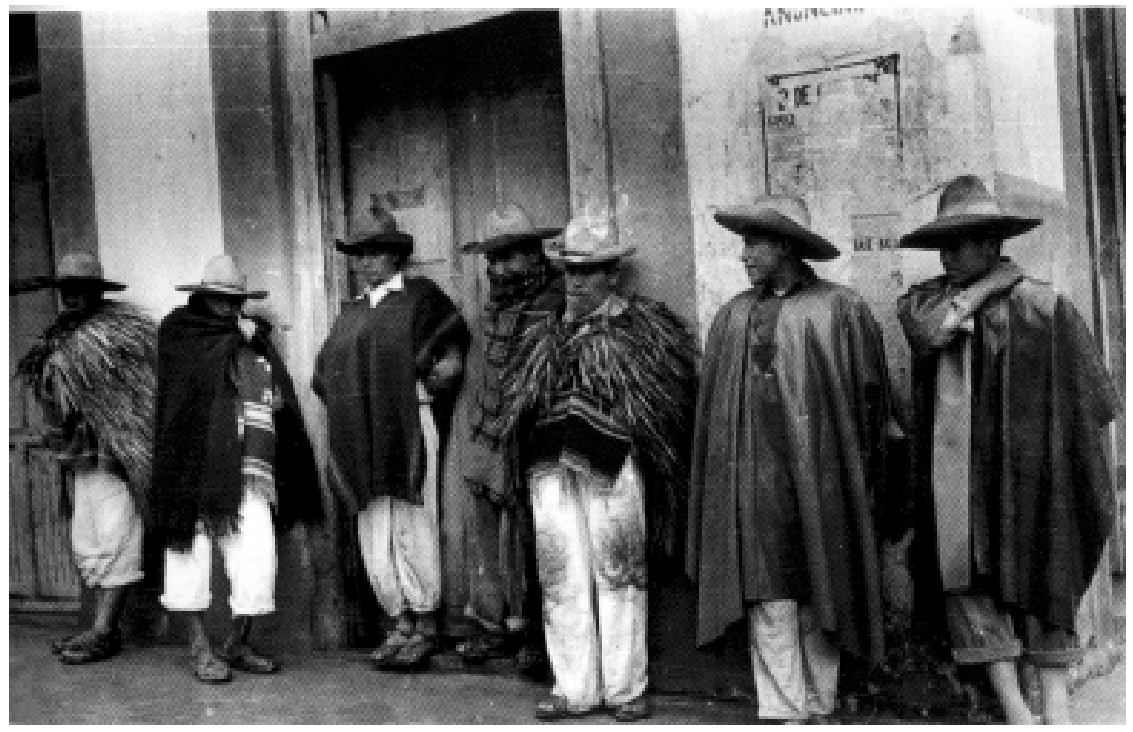
miento, la reducción de la contaminación dentro de las viviendas y en la atmósfera urbana, los servicios de salud reproductiva y los programas integrados de lucha contra enfermedades transmitidas por vectores son acciones relativas al medio ambiente que mejoran las capacidades.

Cada uno de esos factores debe evaluarse, no sólo en lo concerniente a los promedios nacionales sino también en lo tocante a su distribución equitativa. Con frecuencia, las mujeres están en situación desventajosa desde múltiples puntos de vista.

SOluciones a la POBREZA y EL MEDIO AMBIENTE

\section{LA ENERGÍA Y LA POBREZA}

VENTAJOSAS PARA TODOS

Va en aumento el consenso acerca de que sólo un enfoque integrado de los problemas de la pobreza y la degradación del medio ambiente puede conducir al desarrollo sostenible. Entre los elementos fundamentales de una estrategia de desarrollo sostenible se pueden mencionar:

- Aumentar la base de recursos de los pobres, mediante medidas como la reforma de la propiedad de las tierras, la gestión de los recursos comunes con participación de los interesados, las inversiones pú-

blicas en la conservación de tierras y la creación de oportunidades de empleo.

- Efectuar inversiones en servicios e infraestructura de energía alternativa, como los servicios de saneamiento, abastecimiento de agua no contaminada, educación, atención de la salud y otros.

- Apoyar las tecnologías «verdes».

- Adoptar políticas de fijación de precios que no propicien el derroche en el uso de recursos, como los de electricidad, agua y fertilizantes.

El aumento del consumo de energía se asocia con las economías avanzadas, así como con mayores esperanzas de vida y más altos niveles de educación y de otros indicadores de desarrollo social. La correlación no es precisa; entre las economías industrializadas, por ejemplo, en los Estados Unidos de América hay niveles más altos de consumo de energía per cápita o por dólar de PIB que en los países europeos o el Japón. En particular, en muchos casos es posible lograr el desarrollo social sin altos niveles de consumo de energía, como ocurre 
por ejemplo en el estado de Kerala (India), o en Sri Lanka.

Además, un alto consumo de energía también puede no producir un crecimiento económico si está mal orientado, como ocurrió en la Unión Soviética, pero no hay ejemplos de que un crecimiento económico sustancial se haya producido sin el correlativo aumento del consumo de energía, siendo éste uno de los enigmas fundamentales del desarrollo.

Todos los modelos de desarrollo apuntan al crecimiento económico; no obstante, si todos los países consumieran energía a la misma escala que los Estados Unidos de América o incluso los países europeos, se agotarían rápidamente las fuentes de energía y los productos secundarios del uso indeseable de la energía causarían, en el mejor de los casos, una sobrecarga del medio ambiente para absorber dichos productos secundarios. La cuestión es encontrar los medios para que los países más ricos reduzcan los niveles de consumo y que los países y pueblos más afectados salgan de la pobreza sin causar daños de gran magnitud a las economías o a la ecosfera.

Salir de la pobreza no es sólo cuestión de encontrar maneras de incrementar el consumo de energía, sino que es necesario cambiar los tipos de energía que se utilizan.

Las fuentes de energía de los pobres son ineficientes, contaminantes e insalubres. Los pobres pagan precios por unidad de luz o calor emitidas muy superiores a los precios que pagan los ricos, incluido el tiempo que aquellos gastan en obtener o recoger combustible. Las cocinas que queman combustibles de biomasa utilizan sólo un 15\% de la energía potencial de ese combustible. Las estufas a carbón o queroseno tienen una eficiencia de un 50\% . La electricidad y los quemadores de gas propano convierten un 65\% de la energía.

Un estudio realizado en Pakistán indicó que casi un $90 \%$ de los hogares pobres dependen de combus- tibles de biomasa para cocinar y que la mayoría de ellos utilizan queroseno en lugar de electricidad para el alumbrado. En cambio, más de un tercio de los hogares más acomodados utilizan gas para cocinar y en la mayoría de ellos hay alumbrado eléctrico.

La cocción de alimentos con combustibles de biomasa produce hollín y otras sustancias ${ }^{13}$ que causan infecciones agudas a las vías respiratorias, trastornos crónicos por obstrucción pulmonar, cáncer de pulmón y problemas oculares, así como bajo peso al nacer. ${ }^{14}$ El carbón quemado a cielo abierto o en cocinas produce azufre y toxinas como arsénico, floruros y plomo. Los efectos de esos contaminantes se agravan cuando la ventilación es deficiente.

Cuando no se cocinan suficientemente los alimentos o no se hierve el agua adecuadamente debido a la escasez o la ineficiencia del combustible, también se contribuye a la desnutrición, los trastornos digestivos y los parásitos intestinales.

Cuando las mujeres reúnen leña y otros combustibles, deben dedicar tiempo a esas tareas y corren riesgo de lesiones. Un estudio realizado en la República Unida de Tanzania ${ }^{15}$ indicó que en las zonas rurales, las mujeres en buenas condiciones físicas acarrean cada año 25 toneladas métricas para la recolección de leña, mientras que la proporción de ese total para los hombres es muy baja. Un estudio realizado en Addis Abeba comprobó que quienes recogen combustible, que a menudo acarrean cargas casi iguales a sus propios pesos, con frecuencia tropiezan, caen y se fracturan los huesos, o padecen problemas oculares, dolores de cabeza, reumatismo, anemia, dolores internos, toráxicos y de espalda y abortos espontáneos. ${ }^{16}$

Las familias pobres dedican a recoger combustible el doble de tiempo que las que están en mejor posición económica. ${ }^{17}$ Las familias más ricas gastan cantidades hasta 30 veces superiores en energía, lo cual es menos contaminante, más eficiente y causa menos agobios, además de que la adquieren a pre- 
cios preferenciales. El costo de la electricidad, particularmente el que pagan las elites urbanas, con frecuencia está subsidiado.

Los pobres pagan precios unitarios más altos por la energía en cantidades pequeñas: productos como pilas, recarga de pilas, velas, queroseno y carbón. Un estudio realizado en Uganda puso de manifiesto que las familias rurales y periurbanas gastan más de diez dólares mensuales en velas, alumbrado, queroseno, pilas secas y recarga de baterías de automóviles. Hay en el país más hogares que obtienen electricidad de baterías de automóviles que los que están conectados a la red pública de distribución de electricidad.

Las acciones normativas para corregir esas situaciones no necesariamente han tener un costo prohibitivo y podrían generar economías en el largo plazo. El suministro de energía solar suele ser más económico que la prolongación de las redes de distribución de electricidad. Como resultado de los subsidios o de las garantías crediticias es posible que las personas tengan mayor acceso a artefactos de cocina de bajo consumo de combustible. Los subsidios a los precios de la electricidad que pagan los más ricos podrían transferirse hacia combustibles menos contaminantes para los pobres.

DeSARROLLO RURAL y POBLACIÓN

El efecto del aumento de la población en zonas rurales puede ser positivo o bien negativo. Por ejemplo, una gradual transición de densidades de población muy bajas hasta densidades moderadas, puede alentar nuevas prácticas agrícolas, propiciar mayores rendimientos y apoyar poblaciones de mayor magnitud. Ese proceso tal vez haya alentado el desarrollo de la agricultura sedentaria intensiva. ${ }^{18} \mathrm{Al}$ aumentar la densidad de la población rural, aumenta la mano de obra disponible para combatir incendios, trabajar en obras de infraestructura, como los canales de riego y las terrazas y mejorar los suelos.

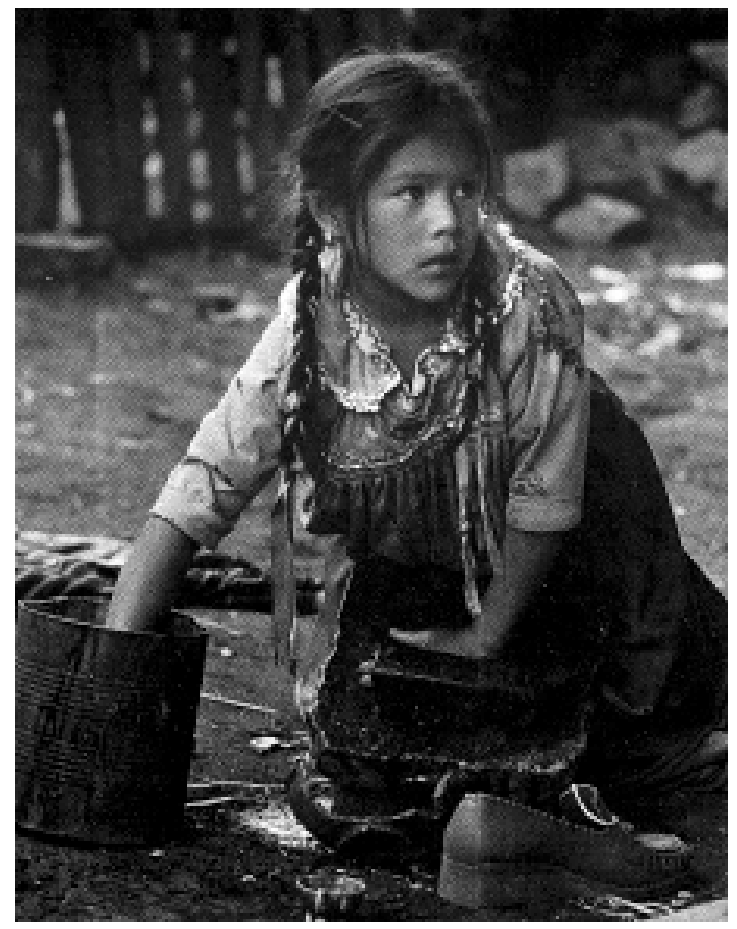

Pero hay muchos casos en que el crecimiento de la población ha perjudicado tanto a las personas como a su medio ambiente. ${ }^{19}$ En los últimos 50 años, el rápido crecimiento de la población se ha duplicado y ha hecho que este aumento en las poblaciones rurales pobres resulte más rápido que la capacidad de éstas para adaptarse. Se ha reducido pronunciadamente su base de recursos debido al uso excesivo y la explotación comercial. En ausencia de excedentes para la inversión, también han permanecido invariables las tecnologías de que disponen las poblaciones rurales pobres.

El sostenido aumento del rendimiento agrícola y la continua mejora de la calidad de vida dependen de complejas influencias recíprocas entre las condiciones del medio ambiente, la disponibilidad de tecnología y la organización social, y las opciones relativas al uso del suelo. Las más altas densidades poblacionales requieren eficaces adaptaciones a nuevas circunstancias. Eventualmente, es posible que el mayor adelanto quede constreñido por límites naturales, por 

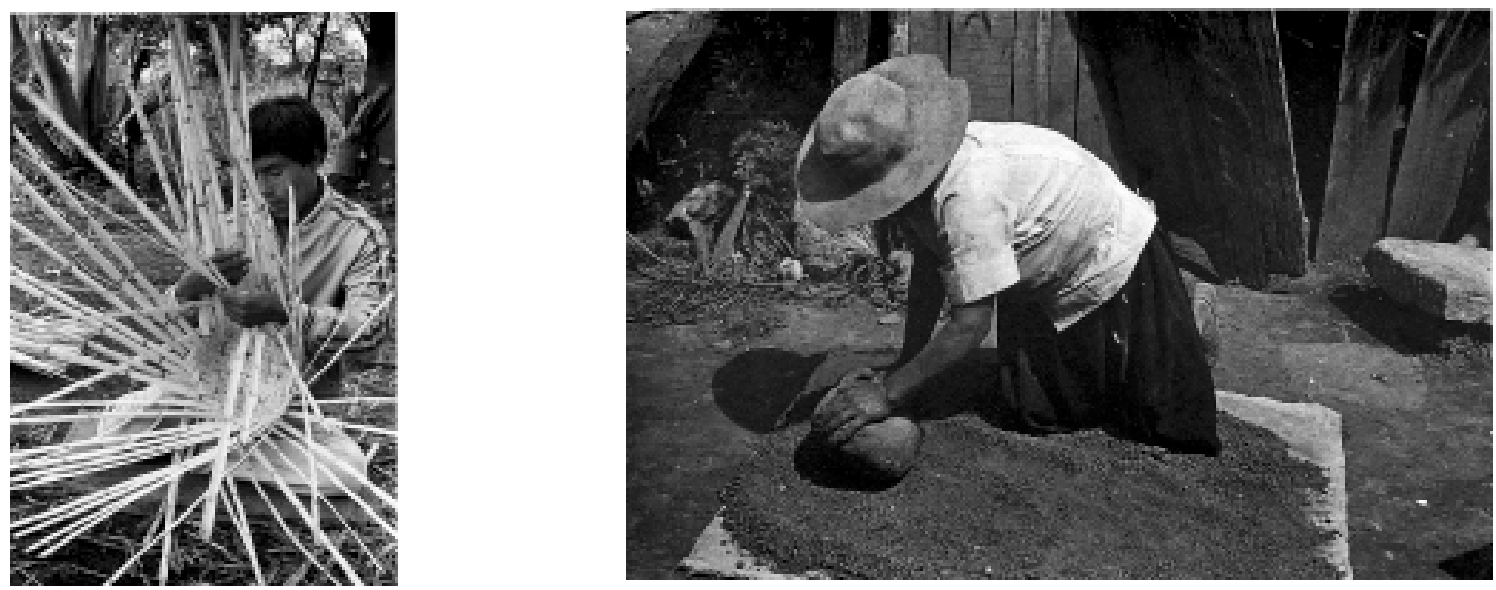

ejemplo, las cantidades de agua de riego, por consecuencias tecnológicas, como la degradación de los suelos debida a la utilización reiterada de fertilizantes químicos, por decisiones políticas relativas al uso del suelo y la organización social o por factores económicos, como la pobreza.

Las comunidades que disponen de acceso a mejores tecnologías y a inversiones sociales, como la educación y la atención universal de la salud, incluidos los servicios de salud reproductiva, los han aprovechado bien para conservar los recursos y establecer economías rurales viables; hay ejemplos de ello en Kerala (India) y en partes de Sri Lanka. En esas comunidades hay menor desigualdad de género, los matrimonios se llevan a cabo a mayor edad, hay menores tasas de fecundidad y el crecimiento de la población es más lento, todo ello pese a los bajos niveles de ingresos.

En muchas zonas rurales, merced a la agricultura intensiva se han logrado aumentar los rendimientos, proporcionando alimentos más baratos para crecientes poblaciones urbanas, en lugar de medios de vida para poblaciones rurales. La agricultura comercial y la tala de árboles practicada por individuos en tierras comunes pueden ser sumamente redituables en la medida en que se disponga de insumos y se conserven los recursos, pero los beneficios raramente llegan a las comunidades locales. Lo común es que los campesinos pobres utilicen excesivamente los recursos residuales de tierra, agua y madera, una vez que las operaciones comerciales se han servido de ellos. Los resultados combinados de esas situaciones pueden percibirse en laderas desnudas, menores caudales de los cursos de agua, inundaciones, sequías y desaparición de las especies silvestres.

Recientes estudios de la Revolución Verde en la India ${ }^{20}$ ponen de manifiesto que al aumentar la productividad hubo mayores incentivos para ampliar las zonas cultivadas. En las zonas donde los bosques eran de propiedad común se condujo a la deforestación, debido a que no hay control sobre el uso de estas tierras. Otros estudios han mostrado que la Revolución Verde ha beneficiado principalmente a los grandes terratenientes y a los usuarios de bienes de propiedad común, presumiblemente debido a que son quienes tienen mayores recursos para efectuar inversiones y mayores perspectivas de obtener utilidades. La carencia de tierras entre ex agricultores de subsistencia y su empobrecimiento debido a la pérdida de los bienes de propiedad común han sido consecuencias involuntarias de la mencionada Revolución.

Los derechos de propiedad individuales pueden proporcionar una motivación superior para la protección individual de la base de recursos, pero no con- 
trarrestan automáticamente los efectos de las cantidades de personas ni de la explotación comercial. ${ }^{21}$ Es posible que sea necesario limitar los derechos de propiedad individual aplicando medidas de protección de los bienes comunes: muchas de las principales pesquerías del mundo se han agotado debido al excesivo aprovechamiento comercial y está por demostrarse que una política pública de limitación en la captura de peces pueda restaurar esas pesquerías.

\section{URBANIZACIÓN}

La concentración de personas posibilita las economías de escala en los costos de transporte, producción y consumo y proporciona protección, como el abastecimiento de agua no contaminada y un saneamiento eficaz. Pero la concentración también puede agravar las cargas y requerir tecnologías más inclusivas, y a veces más caras, para una protección eficaz y sostenible de los seres humanos y de su medio ambiente.

La urbanización ha sido uno de los acontecimientos más notables del último siglo. En África, por ejemplo, en 1900 sólo un 5\% de la población vivía en zonas urbanas, en 1960, un $20 \%$ y en la actualidad, un 38\% . El crecimiento anual de la población urbana en África es el más alto del mundo y llega a más del $4 \%$. Le sigue de cerca la región de Asia y el Pacífico. La población urbana, que ahora es un 35\% del total, aumentó a razón del 2,6\% anual entre 1995 y 2000, en comparación con el $0,7 \%$ anual de la población rural.

En las regiones menos adelantadas se duplicarán en los próximos 30 años las cantidades de habitantes urbanos, desde 1,900 millones hasta 3,900 millones. A las ciudades, impulsoras del desarrollo económico y social, corresponde actualmente una porción grande y cada vez mayor de la demanda de recursos. Algunos análisis indican que las zonas urbanas, donde hay poco más de la mitad de los habitantes del mun- do, producen un $80 \%$ de las emisiones de carbono, consumen un $75 \%$ de todas las maderas y un $60 \%$ del agua dulce extraída para usos humanos (incluida el agua para cultivos de regadío consumidos por residentes urbanos). ${ }^{22}$

Actualmente, hay casi 3,000 millones de personas que viven en zonas urbanas. Más del $75 \%$ de la población de América del Norte, Europa y América Latina reside hoy en ciudades y en todo el mundo hay 411 ciudades con poblaciones superiores a un millón de habitantes, en comparación con 326 en 1990. En Europa occidental y América del Norte, en contraste con la mayoría de las demás regiones, hay una tendencia a que la población salga de las grandes ciudades para residir en los suburbios y en centros urbanos más pequeños.

Hacia el año 2015, 1,600 millones de personas vivirán en ciudades de más de un millón de habitantes, y 622 millones, en ciudades de más de cinco millones de habitantes. En las regiones menos adelantadas aumentarán pronunciadamente las cantidades de residentes urbanos en los próximos 15 años, pasando de 1,900 millones a 2,900 millones (en las regiones más desarrolladas el aumento será de 900 millones a 1,000 millones). Hacia el año 2030, la mayoría de las personas de todas las principales regiones vivirán en ciudades. Un aumento en esta escala tendrá graves consecuencias para la calidad de la vida y los ámbitos circundantes.

En el decenio de 1970, las Naciones Unidas acuñaron el término megaciudades para describir a las poblaciones que contaban con diez millones o más de habitantes. En 1975 había cinco megaciudades en todo el mundo. En la actualidad hay 19, y para el año 2015, su número aumentará hasta 23 (cuadro 1).

En muchas partes del mundo en desarrollo, las ciudades crecen al doble del aumento demográfico. Cada día, unas 160,000 personas se trasladan desde las zonas rurales hacia las ciudades. Este explosivo crecimiento urbano suele deberse tanto a los facto- 
Cuadro 1. Megaciudades del mundo: 1975, 2000 y (proyecciones) 2015

POBLACIÓN EN MILLONES

\begin{tabular}{|c|c|c|}
\hline 1975 & 2000 & 2015 \\
\hline Tokio $(19,8)$ & Tokio $(26,4)$ & Tokio $(26,4)$ \\
\hline Nueva York $(15,9)$ & México D.F. $(18,1)$ & Mumbai $(26,1)$ \\
\hline Shanghai $(11,4)$ & Mumbai $(18,1)$ & Lagos $(23,2)$ \\
\hline México D.F. $(11,2)$ & San Pablo $(17,8)$ & Dhaka $(21,1)$ \\
\hline \multirow[t]{19}{*}{ y San Pablo (10) } & Shanghai (17) & San Pablo $(20,4)$ \\
\hline & Nueva York $(16,6)$ & Karachi $(19,2)$ \\
\hline & Lagos $(13,4)$ & México D.F. $(19,2)$ \\
\hline & Los Ángeles $(13,1)$ & Nueva York $(17,4)$ \\
\hline & Kolkata $(12,9)$ & Yakarta $(17,3)$, \\
\hline & Buenos Aires $(12,6)$ & Kolkata $(17,3)$ \\
\hline & Dhaka $(12,3)$ & Delhi $(16,8)$ \\
\hline & Karachi $(11,8)$ & Metro Manila $(14,8)$ \\
\hline & Delhi $(11,7)$ & Shanghai $(14,6)$ \\
\hline & Yakarta (11) & Los Ángeles $(14,1)$ \\
\hline & Osaka (11) & Buenos Aires $(14,1)$ \\
\hline & Metro Manila $(10,9)$ & El Cairo $(13,8)$ \\
\hline & Beijing $(10,8)$ & Estambul $(12,5)$ \\
\hline & Río de J aneiro $(10,6)$ & Beijing $(12,3)$ \\
\hline & y El Cairo $(10,6)$ & Río de Janeiro $(11,9)$ \\
\hline & & Osaka $(11,0)$ \\
\hline & & Tianjin $(10,7)$ \\
\hline & & Hyderabad $(10,5)$ \\
\hline & & y Bangkok $(10,1)$ \\
\hline
\end{tabular}

res de expulsión de ámbitos rurales deteriorados, entre ellos la pobreza, la carencia de tierras y la falta de oportunidades de trabajo, como a factores de atracción, entre ellos, mejores empleos y servicios sociales en las ciudades.

Los migrantes suelen comprobar que sus vidas se hacen más difíciles. El crecimiento más acelerado se produce en las ciudades pequeñas, que suelen carecer de infraestructura y en asentamientos irregulares en torno a muchas ciudades importantes. En África, un $37 \%$ de los residentes urbanos viven en asentamientos extraoficiales de ese tipo, en Asia, el 18\%, y en América Latina y el Caribe, 9\%. En muchas ciudades, la proporción va del $25 \%$ al $30 \%$ - por ejemplo, viven en ese tipo de viviendas cua- tro millones de los 10,6 millones de residentes en Río de Janeiro-, algunos aferrados precariamente a laderas empinadas, en llanuras inundables o en zonas de alta contaminación, donde nadie optaría por vivir. Los asentamientos densos, particularmente si están mal construidos, son sumamente vulnerables a catástrofes, como inundaciones, tormentas 0 terremotos.

\section{Contaminación}

El rápido crecimiento industrial y la concentración de poblaciones urbanas se combinan para producir contaminación en el agua y el aire. Suelen verterse aguas residuales sin tratamiento en cursos de agua 
locales, junto con los desechos industriales. Los países en desarrollo, en su mayoría, carecen de recursos para vigilar las descargas de residuos sólidos o de contaminantes químicos modernos o para darles un tratamiento adecuado.

A medida que va aumentando la población urbana, se requiere que mayores cantidades de personas compartan el agua de que se dispone. La organización londinense Water Aid informa que las mayores ciudades del mundo ya están agotando sus suministros de agua. Algunos centros urbanos, entre ellos Nueva Delhi, Santiago y México, D.F. están obteniendo agua de lugares cada vez más distantes. Las ciudades de la India septentrional y China han hecho descender peligrosamente la napa en las zonas circundantes.

La mayor cantidad de habitantes redunda en más contaminación del aire. En diez de las mayores ciudades de la India, las cantidades de partículas en suspensión en el aire son entre tres y cinco veces mayores que las normas de la OMS. Yakarta es una entre muchas ciudades asiáticas contaminadas por la quema de basura y los escapes de vehículos a motor Según se informa, Manila tiene en el aire niveles de partículas suspendidas - las pequeñas partículas sólidas dispersadas de los plaguicidas, el amianto y miles de otros productos- mayores que en Nueva York Londres o Tokio.

La mayoría de las ciudades del mundo producen cantidades mayores de desechos y otros residuos que las que pueden manejar. La principal red de desagües cloacales de Manila fue diseñada a comienzos del siglo XX, al servicio de unas 500,000 personas. Sólo un $11 \%$ de la población de la zona metropolitana de esta ciudad cuenta con conexiones a los drenajes públicos. En las zonas que no tienen servicios suficientes, las aguas vertidas se desbordan hacia canal etas junto a las calles, pozos a cielo abierto y canales, hasta llegar a colectores sobrecargados, desde donde esas aguas sin depuración son bombeadas hacia la bahía de Manila o flotan con las mareas.
En cuanto a la Ciudad de México, hay tres millones de personas en zonas periféricas que no están conectadas a los drenajes públicos. Los acuíferos subterráneos están gravemente contaminados.

En muchas ciudades, no se recogen entre un $30 \%$ y un $50 \%$ de los desechos. Incluso en regiones más desarrolladas hay dificultades para absorber el constante aumento de residuos que conlleva el aumento del consumo. En los países de la ex Unión Soviética, las reducciones en los sistemas de recolección y eliminación han excedido a la declinación del consumo. En la Federación Rusa, de los 130 millones de metros cúbicos de residuos sólidos de los hogares recolectados por las municipalidades en 1997, sólo un $3 \%$ Ilegaron a las centrales de procesamiento y a los incineradores.

\section{Pérdida de tierRas de CULTIVo}

La urbanización también afecta la producción alimentaria, pues elimina tierras agrícolas a medida que las ciudades van creciendo y reduce el número de explotaciones agrícolas familiares a medida que mayor cantidad de agricultores emigran hacia las ciudades. Por ejemplo, entre 1987 y 1992, China perdió cada año casi un millón de hectáreas de tierras de cultivo debido a la urbanización y la ampliación de la red vial y las industrias. En los Estados Unidos de América, el crecimiento urbano consume cada año al rededor de 400,000 hectáreas. ${ }^{23}$

Al mismo tiempo, las personas están cultivando cada vez más alimentos en zonas urbanas. En todo el mundo, unos 200 millones de habitantes urbanos están cultivando alimentos y proporcionando a unos 1,000 millones de personas al menos parte de sus alimentos. Por ejemplo, en Accra (Ghana), Ias huertas urbanas proporcionan a la ciudad un $90 \%$ de sus verduras. En Dar es Salaam (República Unida de Tanzania), uno de cada cinco adultos cultiva frutas 0 verduras. 
Los lotes dedicados a huertas y los cultivos en las azoteas tienen beneficios adicionales. Reducen la reflexión de luz y calor y mitigan la captura de este último. Pueden contribuir a eliminar los contaminantes producidos por vehículos a motor, la industria y la producción de energía.

Las zonas urbanas también afectan ámbitos regionales y mundiales debido a su producción de gases de efecto invernadero y a la generación de los componentes de la lluvia ácida.

Las condiciones naturales, entre ellas el clima, la altitud, la topografía y las pautas de vientos y precipitación afectan la capacidad de las ciudades para dispersar los contaminantes atmosféricos y determinar los efectos de éstos sobre sus ámbitos inmediatos. Los problemas de contaminación atmosférica en Santiago de Chile son tan graves y tan intensos como en una ciudad mucho mayor, São Paulo, aun cuando las emisiones de ésta última son diez veces más altas.

\section{Problemas del CRECIMIENTO}

Algunas de las mayores ciudades del mundo están creciendo más lentamente que en el pasado, no obstante, va en aumento su efecto sobre el medio ambiente y empeoran las condiciones locales. Algunas ciudades en rápido crecimiento (por ejemplo, Curitiba y Puerto Alegre, en el Brasil) adoptaron políticas que han mejorado y protegido las condiciones de su medio ambiente. Sin embargo, la mayoría de las ciudades en rápido crecimiento enfrentan graves problemas de salud ambiental y la agravación de las condiciones, particularmente en zonas de nuevos asentamientos en donde son deficientes las instituciones de administración y reglamentación del crecimiento.

El crecimiento de ciudades de tamaño entre pequeño e intermedio en África, Asia y América Latina plantea problemas especiales, particularmente en el abastecimiento de agua, el saneamiento y la recolección de desechos. ${ }^{24}$ Los sistemas de planificación y reglamentación de esas ciudades suelen ser rudimentarios. Tales ciudades no reciben las inversiones y la atención que pueden tener las grandes ciudades y no están en condiciones de lograr economías de escala comparables en la provisión de servicios, el uso del suelo, los transportes y el abastecimiento de agua y energía.

En la mayoría de los países en desarrollo, el rápido crecimiento urbano, generado por la inmigración y el aumento natural de la población, está desbordando la capacidad para proporcionar servicios de salud. Va en aumento la migración de mujeres jóvenes del campo hacia la ciudad en busca de, entre otras cosas, mejores servicios de salud, lo que aumenta la presión, en particular, sobre los servicios de salud reproductiva. ${ }^{25}$ Según las proyecciones de las Naciones Unidas, hacia el año 2020 habrá mayor cantidad de mujeres entre 15 y 39 años de edad en las ciudades que en el campo. En Kenya, un 35\% de las campesinas tienen entre 15 y 39 años de edad, para las mujeres residentes en ciudades, esa proporción es de 53\%, y se han comprobado diferencias similares en Bangladesh, Haití, Indonesia, Nicaragua y Yemen.

En general, las mujeres que residen en ciudades quieren tener una menor cantidad de hijos que las de zonas rurales, pero el acceso a los servicios de planificación de la familia no las ayuda a satisfacer esas aspiraciones. Las zonas periurbanas suelen tener deficientes servicios de salud reproductiva. Las clínicas en zonas centrales de las ciudades tal vez no estén abiertas a horarios cómodos para muchos residentes de la zona metropolitana o para quienes trabajan.

LAS PAUTAS DE DESPILFARRO EN EL CONSUMO

El consumo es un factor de importancia crítico en la relación entre población y la alteración ambiental. Casi todas las actividades humanas tienen repercusiones sobre los recursos naturales: para proporcionar alimentos, vivienda, ropa y transporte se utilizan recur- 
sos como las tierras de cultivo, el agua, el petróleo, el gas y la madera. Además, la mayoría de las actividades humanas también producen residuos que se incorporan al aire, el agua y los suelos, a menudo con escaso o ningun tratamiento para mitigar sus efectos sobre el medio ambiente.

Mientras el crecimiento de la población entraña el aumento de la demanda sobre los recursos, los efectos ambientales de una población dada dependen de la combinación de las cantidades de seres humanos, los niveles de consumo y las tecnologías de extracción y generación de que se disponga. ${ }^{26}$

En el siglo XX, el consumo de bienes y servicios aumentó hasta niveles sin precedentes, impulsando la expansión de la economía mundial y cambiando las realidades de miles de millones de vidas de seres humanos. Pero hay grandes cantidades de personas que han quedado al margen del aumento explosivo en el consumo. Actualmente, hay una gran «discrepancia en el consumo»: en todo el mundo, el $20 \%$ de los habitantes viven en los países de más altos ingresos y efectúan un $86 \%$ del total de los gastos que entraña el consumo privado; para el $20 \%$ de los más pobres, en cambio, ese porcentaje es de sólo 1,3\% (cuadro 2). ${ }^{27}$

Un niño que nazca hoy en un país industrializado agregará durante el curso de su vida al consumo y la contaminación más de lo que 30 a 50 niños nacidos en países en desarrollo (cuadro 3) . ${ }^{28}$ Actualmente, la quinta parte de la población mundial residente en países industrializados produce más de la mitad del anhídrido carbónico emitido hacia la atmósfera, mientras que el quinto más pobre produce únicamente $3 \% .{ }^{29}$ Sólo los Estados Unidos de América, que tienen un 4,6\% de la población mundial, emiten el $25 \%$ de los gases de efecto invernadero en todo el mundo. ${ }^{30}$

El consumo en los países industrializados tiene efectos directos sobre el mundo en desarrollo. Por ejemplo, casi 1,000 millones de personas residentes en 40 países en desarrollo corren el riesgo de perder el acceso a su fuente principal de proteínas, el pescado, a medida que la pesca excesiva impulsada por la demanda de forrajes y aceites por parte de los países industrializados agrega repercusiones a las existencias de peces, ya diezmada. ${ }^{31}$ Los 111 millones de personas que se agregarán a la población de los Estados Unidos de América en los próximos 50 años aumentarán la demanda de energía en cantidades superiores al nivel actual de consumo de energía de los países de África y América Latina juntos. ${ }^{32}$

Es necesario contar con grandes cantidades de recursos naturales a fin de producir los bienes requeridos de los países industrializados. Esos efectos suelen sentirse en regiones muy alejadas de los lugares donde se extraen los metales o el petróleo, donde se recoge la madera y donde se cultivan los alimentos. El transporte de esos bienes también consume cantidades sustanciales de recursos energéticos. ${ }^{33}$

A medida que va aumentando la riqueza de los individuos y de los países, sus demandas pasan a ser mayores que sus necesidades básicas, multiplicándose los efectos del crecimiento demográfico, incluso

Cuadro 2. Aumento del total de los gastos para consumo, 1970 a 1995, en Billones de dólares EE.UU. (a PRECIOS de 1995) ${ }^{37}$

\begin{tabular}{lcccc}
\hline & 1970 & 1980 & 1990 & 1995 \\
\hline Países industrializados & 8,3 & 11,4 & 15,7 & 16,5 \\
Países en desarrollo & 1,9 & 3,6 & 4,3 & 5,2 \\
\hline
\end{tabular}


en las regiones pobres. $Y$ dada la mundialización de la cultura del consumo de los países occidentales, necesariamente ha de aumentar la demanda de diversos productos, entre ellos automóviles, computadores y acondicionadores de aire, lo cual ha de agregar presión sobre los recursos naturales y la capacidad de los ecosistemas para absorber los residuos. ${ }^{34}$

Pese a los problemas, conectados entre sí, de limitar rápidamente el exceso de consumo y eliminar la demanda del consumo insuficiente, hay algunos indicios de cambios positivos. Los gobiernos y las industrias están incrementando la utilización de recursos renovables y de tecnologías menos contaminantes o cantidad de demandas sobre nuestros recursos medioambientales, pero demandas mucho mayores sobre nuestros recursos morales». ${ }^{35}$

\section{La huella ecológica de la humanidad}

Para medir los efectos sobre el medio ambiente algunos científicos han elaborado un indicador de huella ecológica ${ }^{36}$ que refleja cuáles son las regiones que más consumen determinados recursos, en términos tanto absolutos como per cápita.

En las estimaciones de la huella ecológica interviene el consumo de alimentos, materiales y energía

Cuadro 3. Niveles de CONSUmo, desde los mÁs Ricos hasta los mÁs POBRes ${ }^{38}$

\begin{tabular}{|c|c|c|}
\hline & $\begin{array}{l}\text { PORCENTAJE CONSUMIDO } \\
\text { POR PERSONAS EN PAÍSES } \\
\text { INDUSTRIALIZADOS }\end{array}$ & $\begin{array}{l}\text { PORCENTAJE CONSUMIDO } \\
\text { POR EL } 20 \% \text { MÁS POBRE } \\
\text { DE LAS PERSONAS, EN PAÍSES } \\
\text { EN DESARROLLO }\end{array}$ \\
\hline Total de los recursos de energía & 58 & $<4$ \\
\hline Carne y pescado & 45 & 5 \\
\hline Papel & 84 & 1,1 \\
\hline Vehículos & 87 & $<1$ \\
\hline Líneas telefónicas & 74 & 1,5 \\
\hline
\end{tabular}

no contaminantes y que mejorarán las condiciones para el futuro. Se trata de realizar programas de ordenamiento sostenible que abarquen cantidades cada vez mayores de tierras arboladas. Se está intensificando el debate público acerca de los diversos temas del medio ambiente (inclusive las políticas energéticas y de uso del suelo), y se están llevando a cabo las gestiones para concertar acuerdos internacionales.

No obstante, lo que el economista Herman Daly escribió hace 30 años parecería ser pertinente hoy: una economía sostenible «plantearía mucha menor por parte de la población, en función de la superficie de tierras o de mares biológicamente productivos necesarios para obtener esos recursos naturales 0 , en el caso de la energía, para absorber las correlativas emisiones de anhídrido carbónico. La medición se efectúa en «unidades de superficie». Una unidad de superficie es equivalente a una hectárea de productividad media mundial.

Cada región está representada por un rectángulo, en que el ancho es proporcional a la población, la altura representa el consumo de recursos per cápita y 
la superficie representa el total del consumo en la región. En consecuencia, Asia, que posee una población más de 10 veces superior a la de América del Norte, pero cuyo consumo de recursos per cápita es de sólo un sexto, tiene una huella sólo algo mayor que la de América del Norte.

Este análisis refleja los dos aspectos más importantes del reto que enffrenta la sostenibilidad: el consumo de recursos per cápita y el crecimiento de la población.

En este indicador también se individualizan las zonas de capacidad biológica natural alta y baja y las regiones responsables de «déficit ecológicos», donde el consumo de recursos es superior a los niveles de uso sostenibles. Según el informe Living Planet 2000, en 1996 el consumo mundial fue de 2,85 unidades de superficie por persona, es decir, fue superior en $30 \%$ a la disponibilidad biológica (2,18 unidades).
Los países ricos miembros de la Organización de Cooperación y Desarrollo Económico (OCDE) tenían en 1996 una huella ecológica total de 7,22 unidades de superficie por persona, superior a más del doble de la capacidad biológica, de 3,42 unidades. Los países no miembros de la OCDE tenían una huella ecológica total de 1,81 unidades de superficies por persona, ligeramente inferior a la capacidad biológica, de 1,82 unidades (gráfica 1).

En 1996, África tenía un excedente ecológico de 0,40 unidades de superficie por persona (una huella de 1,33 unidades y una capacidad biológica disponible de 1,73 unidades de superfice). Muchos países africanos disfrutaban de grandes superávit ecológicos y muy pocos países tenían déficit superiores a una unidad de superficie por persona. No obstante, esos superávit son consecuencia de la pobreza generalizada y no de un ordenamiento beneficioso.

Gráfica 1. Huella ecológica por Región, 1996

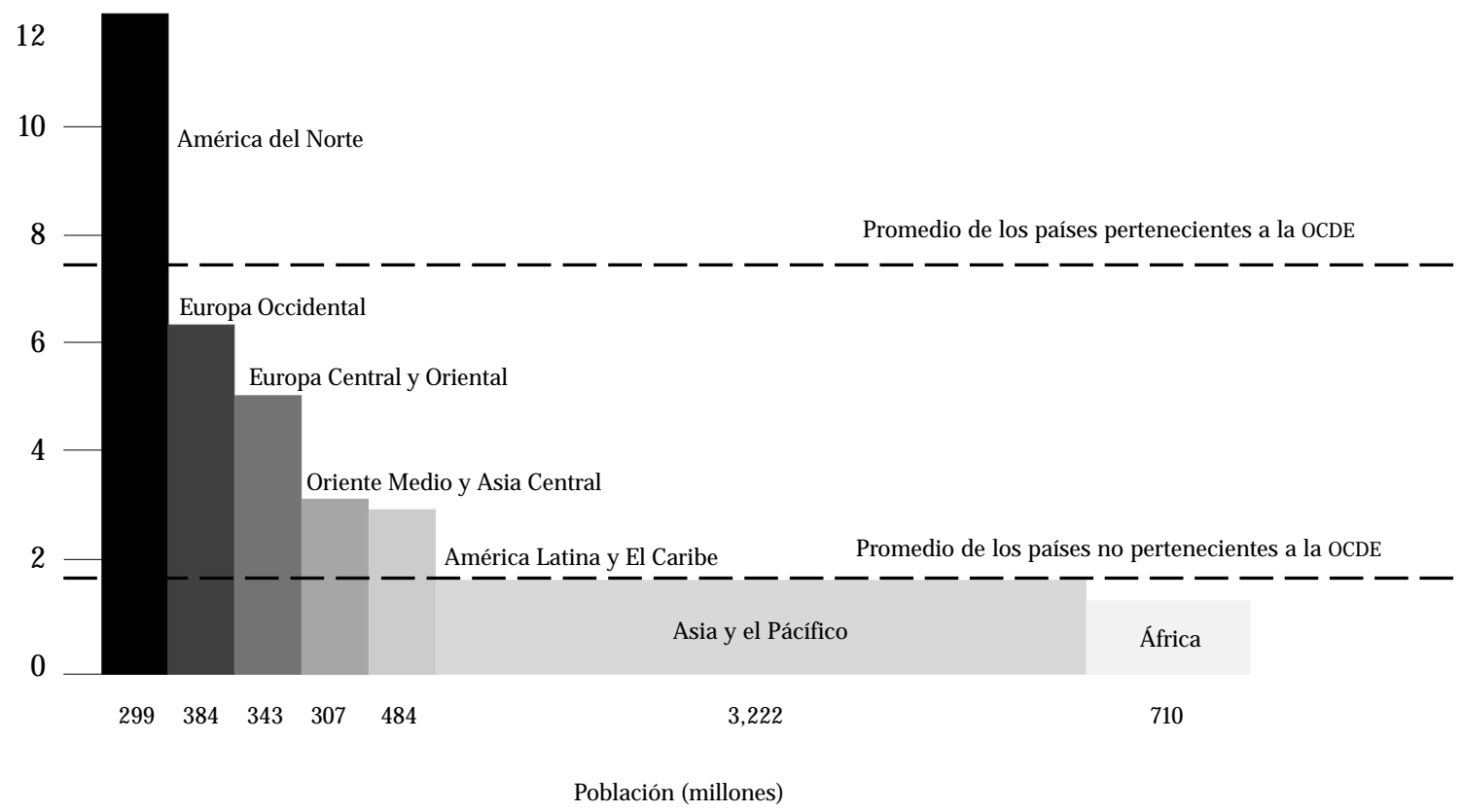

Fuente: Fondo Mundial para la Naturaleza (WWF), Centro de Vigilancia Mundial de la Conservación, Programa de las Naciones Unidas para el Medio Ambiente, Redefining Progress, Center for Sustainable Studies y Norwegian School of Management, 2000. Living Planet Report, 2000. Fondo Mundial para la Naturaleza, Gland, Suiza. 


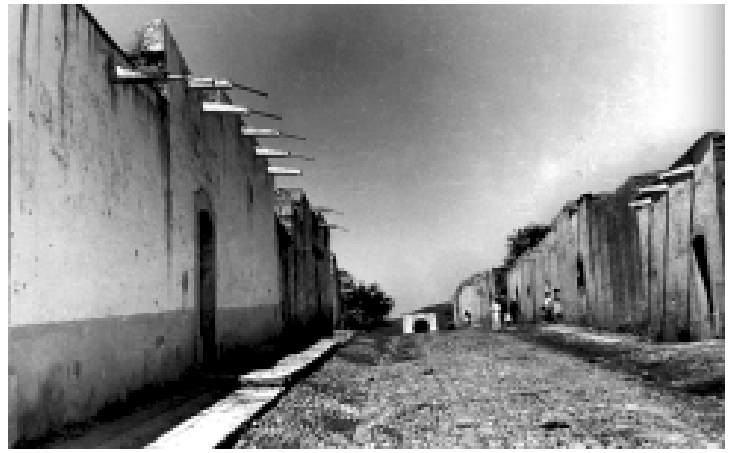

La región con el excedente ecológico más alto del mundo fue la de América Latina y el Caribe, con 3,93 unidades de superficie por persona, debido a su alta disponibilidad biológica natural (6,39 unidades) y a su consumo de recursos relativamente bajo $(2,46$ unidades). Los mayores excedentes per cápita se encontraron en Bolivia, Brasil y Perú.

En la región del Oriente Medio y el Asia central, el déficit ecológico fue de 1,82 unidades de superficie por persona, debido en gran medida al bajo nivel de su capacidad biológica (0,91 unidades). El total de la huella ecológica para la región fue de 2,73 unidades de superficie por persona. Los países con déficit más altos fueron las economías petroleras más ricas, como los Emiratos Árabes Unidos y Kuwait.

El déficit ecológico de Asia y el Pacífico, con 0,67 unidades de superficie por persona, puede atribuirse en parte a la gran magnitud de su población, lo cual reduce la capacidad biológica a 1,11 unidades. El total de la huella ecológica de la zona en 1996 fue de 1,78 unidades de superficie por persona. Los déficit más altos se registraron en Singapur, Japón y Corea del Sur.

En 1996, América del Norte tenía el déficit ecológico más alto del mundo $(5,64$ unidades de superficie por persona), pese a que por su capacidad biológica ocupaba el segundo lugar en el mundo por orden de magnitud (6,3 unidades). En los Estados Unidos de América se registró un déficit ecológico de 6,66 unidades de superficie por persona.
Europa occidental, donde el déficit ecológico fue de 3,35 unidades de superficie por persona, ocupó el segundo lugar entre los más altos del mundo. La huella ecológica llegó a 6,28 unidades, en comparación con una capacidad biológica de 2,93 unidades. Los déficit más altos se registraron en el Reino Unido, Suiza y Dinamarca.

La región de Europa Central y Oriental presentó una huella ecológica de 4,89 unidades de superficie por persona, con una capacidad biológica de 3,14 unidades de superficie y un déficit de 1,75 unidades en 1996. Los déficit más altos se registraron en la República Checa y Estonia.

En el informe Living Planet 2000 se presentan unos cinco componentes también de la huella ecológica: tierras de cultivo, tierras de pastoreo, bosques (leña y productos de la madera, incluido el papel), pesquerías (peces marinos y frutos de mar, inclusive harina y aceites de pescado para alimento de animales) y anhídrido carbónico (consumo de combustibles fósiles más las cantidades netas de energía necesarias para la fabricación de productos manufacturados importados ${ }^{39}$. Estos productos también indican una gran discrepancia en el consumo, entre países desarrollados y en desarrollo.

Por ejemplo, la huella de tierras de cultivo de América del Norte (1,44 unidades de superficie por persona) fue superior al doble del promedio mundial $(0,69$ unidades). La huella de las pesquerías correspondiente a los consumidores de países miembros de la OCDE fue tres veces superior a la de los países no miembros de la OCDE. En 1996, la huella del anhídrido carbónico correspondiente al promedio del consumo en los países de la OCDE fue superior en más de cinco veces a la del consumo en países que no forman parte de dicho organismo. La huella del anhídrido carbónico para América del Norte, siete unidades de superficie por persona, fue equivalente a cinco veces el promedio mundial y más de siete veces los promedios de América Latina y el Caribe, Asia y el Pacífico y África. 


\section{Refugiados del medio ambiente}

El desplazamiento de poblaciones debido a la degradación del medio ambiente ( por desastres naturales, guerra o explotación excesiva) no es un fenómeno reciente. Lo que resulta novedoso es el potencial para grandes desplazamientos de personas resultante de una combinación de agotamiento de recursos, destrucción irreversible del medio ambiente y crecimiento de la población, entre otros factores. ${ }^{40}$ En 1998, cuando un maremoto azotó las costas de Papua Nueva Guinea, se perdieron miles de vidas debido a que los asentamientos humanos estaban ubicados en la costa y las riberas de lagunas. Cuando debido al desbordamiento del río Yangtze se inundaron vastas superficies en China, el desastre fue exacerbado por la deforestación y la erosión causadas por el exceso de población en las riberas del río.

En enero y febrero de 2001, miles de personas perdieron sus viviendas cuando violentos terremotos afectaron a El Salvador, causando mortales deslizamientos de tierras en laderas montañosas que habían sido desbrozadas para dar lugar a cultivos de subsistencia.

Según estimaciones del Banco Mundial, en 1998 había 25 millones de personas desplazadas debido a la degradación del medio ambiente, cantidad que por primera vez en la historia fue superior a la de refugiados a causa de guerras.

Los refugiados desplazados suelen crear amenazas a las zonas donde se radican. La crisis que padeció Ruanda en 1994 creó una corriente de más de 600,000 personas hacia la zona noroccidental de la República Unida de Tanzania, donde los refugiados causaron daños considerables al medio ambiente, al recolectar leña y madera para otros usos, como cazadores furtivos en reservas de animales y al cultivar tierras.

Los refugiados del medio ambiente tienen notables consecuencias económicas, socioculturales y po- líticas. Actualmente, los países desarrollados pagan cada año 8,000 millones de dólares para acoger a los refugiados, lo cual representa un séptimo del apoyo en asistencia exterior aportado a los países en desarrollo.

\section{Notas}

1. Véase: Marguette, Catherine y Richard Bilsborrow, 1997. «Population and Environment Relationships in Developing Countries: A Select Review of Approaches and Methods». En: B. Baudot y W. Moomaw, 1997. The Population, Environment, Security Equation. Macmillan, Nueva York y McNicoll, Geoffrey. 2000. Managing PopulationEnvironment Systems: Problems of Institutional Design. Population Council, Policy Research Division, Working Paper. No. 139. The Population Council, Nueva York.

2. La fórmula fue elaborada a principios del decenio de 1970 como parte de un debate relativo a la contribución de la población a la contaminación del aire en los Estados Unidos de América. Se formuló matemáticamente de manera explícita en Ehrlich, P. R. y J. Holdren, 1971. "Impact of Population Growth". Science 171: 1212-17.

3. Entre algunos ejemplos de amplia distribución cabe señalar: Hinrichsen, Don y Bryant Robey, 2000. «Population and the Environment: The Global Challenge». Population Reports. Series M. No. 15. Population Information Program, J ohns Hopkins University School of Public Health, Baltimore; Harrison, P., 1992. The Third Revolution: Environment, Population and a Sustainable World. I.D. Tauris and Company en asociación con Penguin Books, Londres; y FNUAP, 1992. El estado de la población mundial 1992: Un mundo en equilibrio. FNUAP, Nueva York.

4. Harrison, 1992 y Shaw, R. P., 1993. «Review of Harrison 1992». Population and Development Review 12(1): 189-92.

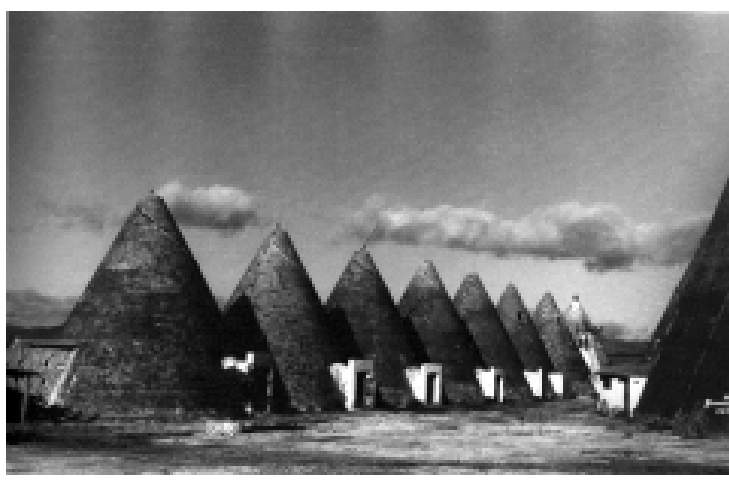


5. Meyerson, F. A. B., 1998a. «Population, Carbon Emissions, and Global Warming: The Forgotten Relationship at Kyoto». Population and Development Review 24(1): 115-30;

Meyerson, F. A. B., 1998b. «Toward a Per Capita-based Climate Treaty: Reply». Population and Development Review 24(4): 804-10 y Meyerson, F. A. B., 2001a. «Population and Climate Change Policy». En: S. Schneider, A. Rosencranz y J. Niles (eds.), en prensa. Climate Change Policy: A Survey. Island Press, Washington, D. C.

6. Pueden encontrarse análisis regionales preparados por: O' Neill, B. C., 1996. «Greenhouse Gases: Timescales, Response Functions, and the Role of Population Growth in Future Emissions». Disertación de doctorado. Nueva York: Earth Systems Group, Department of Applied Science, New York University.

7. Banco Mundial, 2000. World Development Report 2000/ 2001: Attacking Poverty. Oxford University Press, Nueva York.

8. Ibidem.

9. Programa de las Naciones Unidas para el Desarrollo, 1998. Informe sobre desarrollo humano 1998: Consumo para el desarrollo humano. Programa de las Naciones Unidas para el Desarrollo, Nueva York.

10. Por ejemplo, Reed, David y Herman Rosa, 1999. Economic Reforms, Globalization, Poverty and the Environment. Nueva York: Programa de las Naciones Unidas para el Desarrollo. Sitio en Internet: http:// www.undp.org/seed/ pei/publication/ economic.html.

\section{Banco Mundial, 2000. World Development..}

12. Sen, Amartya, 1999. Development as Freedom. Knopf, Nueva York. (Hay traducción al español del FCE).

13. Esos contaminantes abarcan pequeñas partículas de hollín, monóxido de carbono, benceno y formaldehído (Programa de las Naciones Unidas para el Desarrollo, 1997. Energy After Rio: Prospects and Challenges. Nueva York: Programa de las Naciones Unidas para el Desarrollo. Citado en Sudhir Chella Rajan y Ellen Morris, 1999. «Energy as it Relates to Poverty Alleviation and Environmental Protection». Poverty and Environment Initiative Publication Series. Programa de las Naciones Unidas para el Desarrollo, Nueva York. Sitio en Internet: www.undp.org/seed/ pei/ publication/ energy.PDF.

14. Smith, K. R., 1990. «Health Effects in Developing Countries» en J. Pasztor, Janos y L. Kristoferson (eds.). Bioenergy and the Environment. Westview Press. Boulder, Colorado.

15. Programa de las Naciones Unidas para el Desarrollo, 1997.
16. Haile F., 1991. Women Fuelwood Carriers in Addis A baba and the Peri-Urban Forest. Organización Internacional del Trabajo, Ginebra, citado en: Rajan y Morris, 1999.

17. Un estudio realizado en el Pakistán demostró que, en promedio, la quinta parte más pobre de los hogares dedicaron más de tres horas por semana a recoger leña o estiércol. (Pakistan Living Standards Measurement Survey, 1991 citado en: Rajan y Morris, 1999). En lugares aún más áridos y con mayores niveles de explotación, como el Cuerno de África, el tiempo es considerablemente mayor. Las familias que viven en la pobreza necesitan realizar mayores esfuerzos para otros servicios medioambientales, como recoger agua. La mayor parte de esta carga es soportada por las mujeres y los niños.

18. Ésta fue la tesis central del memorable análisis realizado por Boserup. Su trabajo ha sido reimpreso en: Boserup, Ester, 1990. Economic and Demographic Relationships in Development: Essays Selected and Introduced by T. Paul Schultz. Johns Hopkins University Press, Baltimore, Maryland.

19. El trabajo de Sara J. Scherr proporciona numerosos ejemplos. Esta analista ha publicado trabajos para contrarrestar la atribución superficial de los efectos negativos al crecimiento de la población, pero proporciona valiosas percepciones acerca de las delicadas condiciones que deben satisfacerse para lograr mejores resultados. Véase: Scherr, Sara J., 1999. «PovertyEnvironment Interactions in Agriculture: Key Factors and Policy Implications». Ponencia preparada para el Seminario Práctico de Expertos sobre la Pobreza y el Medio Ambiente, patrocinado por el Programa de las Naciones Unidas para el Desarrollo y la Comisión Europea, Bruselas, Bélgica, 20 y 21 de enero de 1999. Programa de las Naciones Unidas para el Desarrollo, Nueva York; Scherr, Sara J., 2000. «A Downward Spiral: Research Evidence on the Relationship between Poverty and Natural Resource Degradation». Food Policy 25: 47998 y Templeton, Scott R. y Sara J. Scherr, 1999. «Effects of Demographic and Related Microeconomic Change on Land Quality in Hills and Mountains of Developing Countries». World Development 27(6): 903-18. Véase también: Leach, Melissa y James Fairhead, 2000. «Challenging Neo-Malthusian Deforestation Analyses in West Africa's Dynamic Forest Landscapes». Population and Development Review 26(1): 17-43.

20. Rosenzweig, Mark, 2000. «Study of the Demographic Effects of the Green Revolution in India». Ponencia presentada en el Seminario Práctico de RAND sobre Población, Salud y Medio Ambiente, Santa Monica, California, 11 a 13 de enero de 2001 y Rosenzweig, Mark, 2001. «Population Growth, Economic Change and Forest Degradation in India». Ponencia presentada en la Reunión Anual de la Population Association of America, Washington, D. C., 29 de marzo de 2001. 
21. Véase: Lee, Ronald D., 1991. «Comment: The Second Tragedy of the Commons». En: Resources, Environment, and Population: Present Knowledge, Future Options. Suplemento del volumen 16, 1990: Population and Development Review, editado por Kingsley Davis y Mikhail S. Bernstam. 1991. The Population Council, Nueva York.

22. O'Meara, M., 1999. Reinventing Cities for People and the Planet. Worldwatch Institute, Washington, D. C.

23. Kolankiewicz, Leon, y Roy Beck, 2001. Weighing Sprawl Factors in Large U.S. Cities. Numbers, Arlington, Virginia.

24. Véase: Naciones Unidas, 2001. World Population Monitoring 2001: Population, Environment and Development (EAS/ P/W P.164), págs. 95 y siguientes. Proyecto. Nueva York: División de Población, Departamento de Asuntos Económicos y Sociales, Naciones Unidas.

25. Esta sección se basa en los análisis que figuran en: Brockerhoff, Martin P., 2000. «An Urbanizing World.» Population Bulletin 55(3). The Population Reference Bureau, Washington, D. C.

26. Programa de las Naciones Unidas para el Desarrollo, 1998.

27. Ibidem y Brown, L. y otros, 2001. State of the World 2001. Worldwatch Institute, W. W. Norton \& Co, Nueva York.

28. Ibidem.

29. Ibidem.

30. Brown, L., G. Gardner y B.Halweil, 1999. Beyond Malthus: Nineteen Dimensions of the Population Challenge. Worldwatch Institute, W. W. Norton \& Co, Nueva York.

31. Programa de las Naciones Unidas para el Desarrollo, 1998.

32. Este tema fue originariamente señalado en correspondencia con proyecciones más tempranas (y menores) de la población de los Estados Unidos de América por: Brown, Gardner y Halweil, 1999.

33. World Resources Institute, 1999. World Resources 1998-1999. World Resources Institute, Washington, D. C.

34. Abramovitz, Janet N. y otros, 2000. Vital Signs 2000: The Environmental Trends that are Shaping Our Future. Worldwatch Institute, W. W. Norton \& Co., Nueva York y Brown, y otros, 2001.

35. Daly, Herman E., 1971. «Toward a Stationary State Economy». En: John Harte y Robert Socolow (eds.), 1971. Patient Earth. Holt, Rinehart y Winston, Inc., Nueva York.

36. Los pioneros del enfoque de huella ecológica fueron Mathis Wackernagel y colegas. Véase: Wackernagel, Mathis y William Rees, 1996. Our Ecological Footprint: Reducing Human Impact on the Earth. New Society Publishers, Gabriola Island, British Columbia. Figuran mayores detalles y referencias en: Fondo Mundial para la Naturaleza (WWF), Programa de las Naciones Unidas para el Medio Ambiente, Centro de Vigilancia Mundial de la Conservación, Redefining Progress, Center for Sustainability Studies, y Norwegian School of Management, 2000. Living Planet Report 2000. Fondo Mundial para la Naturaleza (WWF), Gland, Suiza.

37. Programa de las Naciones Unidas para el Desarrollo, 1998.

38. Ibidem.

39. Al igual que lo que ocurre con otros indicadores en que se combinan diversos componentes, los detalles técnicos (como los criterios de ponderación de los elementos) pueden afectar la agregación y las conclusiones. Los componentes aluden más directamente a los aspectos más particularmente vulnerables o fuertes.

40. Esta sección se basa en: Myers, N., 1993. «Environmental Refugees in a Globally Warmed World». Bioscience 43(11): 752-61; y Lonergan, Steve, 1998. «The Role of Environmental Degradation in Population Displacement». Environmental Change and Security Project Report, no. 4.: 5-15. The Woodrow Wilson Center, Washington, D. C.

Este texto forma parte del informe del Fondo de Población de las Naciones Unidas denominado El estado de la población mundial 2001. La versión completa puede consultarse en www.unfpa.org/swp/2001. Se han hecho algunos cambios en la redacción para ajustar esta versión a los criterios editoriales de la Gaceta ecológica.

Fotografías: François Chevalier y Javier Pérez Siller, Viajes y pasiones. Voyages et passions, 1998. IFAL, CEMLA, FCE, páginas 7, 8, 11, 12, 13, 24, 25. César Moreno y Ricardo Barthelemy. En la nostalgia del futuro. La vida en el bosque de Michoacán, 1994. Centro francés de estudios mexicanos y centroamericanos, El Colegio de Michoacán, Gobierno del estado de Michoacán, páginas 15 y 16 . Francisco Martínez (página 7, abajo). Tomada de Blanco, José J oaquín, 1990. Los mexicanos se pintan solos. Crónicas, paisajes, personajes de la Ciudad de México.

Pórtico de la Ciudad de México, México. 
IMPULSO AMBIENTAL es un órgano informativo del Centro de Educación y Capacitación para el Desarrollo Sustentable (CECADESU) que tiene como fin ofrecer información oportuna y confiable en torno a la educación, la capacitación y la comunicación ambientales.

Índice de este número

\section{Editorial}

Perfiles

En los estados

Educación y comunicación ambiental para la participación social

La comunicación educativa: herramienta clave de la cultura ambiental

Viaje por México

Johannesburgo, a diez años de Río

Reunión de productores de medios de comunicación

rumbo a J ohannesburgo 2002

Cursos, seminarios, talleres... y algo más

Género y medio ambiente

Calidad total

Proyecto artístico cultural

En busca de una cultura del agua

A debate

Número 6. Septiembre-octubre 2001

$21.5 \mathrm{~cm} \times 28 \mathrm{~cm}$

24 páginas a dos tintas

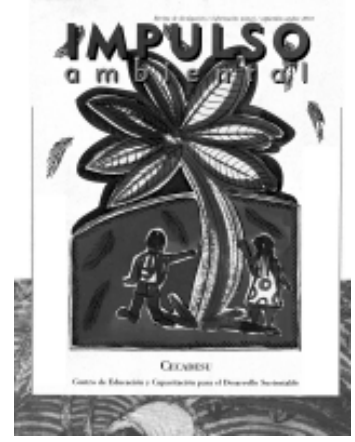

Para mayores informes: Cecadesu. Progreso 3, primer piso, col. del Carmen Coyoacán, C.P. 04100, México, D.F. Tels.: 55546268 y 56583431.

Correos electrónicos: ngonzalez@ semarnat.gob.mx, mdominguez@ semarnat.gob.mx, shernandez@ semarnat.gob.mx.

Página en Internet: www.semarnat.gob.mx/ cecadesu. 